\title{
Opinions of members of the National Civil (Family Proceedings) and Criminal Courts in withholding or withdrawing of life support situations in pediatrics
}

\author{
Jorge O. Selandari, M.D. ${ }^{a}$, María S. Ciruzzi, M.D. ${ }^{a}$, Adriel J. Roitman, M.D. ${ }^{b}$, \\ Fernanda Ledesma, M.D. ${ }^{a}$, Célica Menéndez, M.D. ${ }^{a}$ and Hernán O. García, M.D. ${ }^{a}$
}

\begin{abstract}
Introduction. The possibility of sustaining life functions makes it difficult to distinguish between a dying patient and a patient with chances of survival, raising a dilemma for everyone around them. On the one side, continuing with life support techniques that would only extend an irreversible process and result in physical and psychological damage and harm their dignity. On the other side, withholding or withdrawing life support without an adequate reflection and diagnostic-therapeutic effort which may lead to the death of a potentially recoverable child. In addition, making decisions in this context implies facing barriers that hinder the possibility of pursuing the patient's best interest. Among such barriers, the fear of litigation plays a major role. To what extent is this fear justified?

Objective. To explore the opinions of the members of the National Judiciary regarding the approach to withholding or withdrawing of life support from a legal stance.
\end{abstract}

a. Hospital Ethics Committee. Hospital de Pediatría SAMIC "Prof. Dr. Juan P. Garrahan".

b. Grant holder. School of Law. Universidad de Buenos Aires.

E-mail address:

Jorge O. Selandari, M.D.: jselandari@intramed.net

Funding:

This research study was conducted with the support of the Ramón Carrillo-Arturo Oñativia Continuing Education Scholarship, granted by the National Ministry of Health of Argentina through the Health Research Committee (Comisión Nacional Salud Investiga).

\section{Conflict of interest:}

None.

Received: 5-20-2015

Accepted: 2-10-2016

\section{INTRODUCTION}

Medical science development, in its technological phase, has resulted in the emergence of technologies that allow sustaining life to an extent that was unthinkable not long ago. The need to limit this practice posed by the exercise of certain rights (autonomy, dignity, quality of life), the obligation to avoid causing harm (therapeutic obstinacy or patient neglect), and the increasing active role played by patients and/or their family in the health care relationship make it necessary to consider how to solve these problems without harming the patient nor questioning the responsibility of health care team members. In terms of bioethics, the prevailing concept is that not everything that is technologically feasible is ethically correct. What is the approach to this matter according to the Argentine civil and criminal law? Is withholding/withdrawing of life support (WLS) legally allowed in pediatrics? Does WLS require a legal authorization in pediatrics? Is WLS in a pediatric patient a crime?

\section{OBJECTIVE}

To explore the opinion of members of the National Judiciary (NJ) regarding the approach to WLS from a legal stance.

\section{POPULATION}

Professionals working in the criminal, civil and forensic medicine settings.

\section{METHODS}

Descriptive, cross-sectional, qualitative, quantitative, explorative 
study with a diagnostic analysis. The instrument used in this study was a semistructured, anonymous survey, which included an informed consent (available in the online Annex), administered by the grant holder and/or selfadministered by research subjects themselves. The survey structure was as follows:

a. Personal and professional background.

1. Demographic data.

2. Professional training.

3. Religious background.

b. Case and conceptual background.

c. Case history analysis:

The survey described three hypothetical cases based on situations generally faced by the pediatric health care team, and classified into three categories commonly typified in the ethical analysis of these situations. The first case was the "no chance" situation. The second case was the "unbearable" or extremely poor quality of life situation. Finally, the third case described a patient in a persistent vegetative state. ${ }^{1}$ In addition, it was explained that all cases took place in a context of a good relationship, understanding and agreement among the medical team and the patient's family.

\section{Definition of each category}

1. No chance situation: Treatment will merely delay death, without significantly relieving suffering.

2. Unbearable situation: In the face of progressive disease, additional treatment may only cause further suffering, despite the possibility that it might have some potential benefit on the underlying condition.

3. Persistent vegetative state: Medical condition characterized by the absence of voluntary interaction with the outside world, lack of awareness of the inner world, with no reasonable possibility of recovery after 12 months of assistance. The patient feels no pain

TABLE 1. Hypothetical cases described in the survey

\section{Case 1. No chance situation}

Mariela was an 11-year-old girl with acute myeloid leukemia. The intention had been to perform bone marrow transplantation after chemotherapy. She tolerated treatment poorly and developed sepsis (severe systemic infection) and difficult breathing. She was intubated and connected to a ventilator in the intensive care unit, but her condition continued to deteriorate and required progressively increasing ventilator settings. In spite of chemotherapy, leukemia was still active, which in her present context indicated a situation with no reasonable chances of recovery. Physicians and parents agreed not to escalate life support (e.g., use of ventilator, dialysis or invasive procedures, such as catheterization, etc.) or start cardiopulmonary resuscitation in the event of a cardiac arrest. Mariela had multiple organ failure, cardiac arrest and died; cardiopulmonary resuscitation was not attempted.

\section{Case 2. Unbearable or poor quality of life situation}

A first-time mother went into labor at 41 weeks of gestation and required an emergency C-section. She delivered a $2700 \mathrm{~g}$ male infant named Ramón, who was relatively small for his gestational age. The baby was not breathing; he was resuscitated but had seizures within the following four hours. He was unresponsive and placed on mechanical ventilation (MV) until he was 32 days of life. At 45 days old, he required MV once again due to apneic episodes (a temporary absence or cessation of breathing), which resulted in a respiratory infection, and required increasing ventilator settings. At 65 days old, he had his first major bronchial-obstructive reaction, accompanied by crying and generalized cyanosis requiring resuscitation and sedation. These episodes were recurrent and progressively worsened during the course of hospitalization, and in spite of several therapeutic strategies, at 9 months old he required continuous mechanical ventilation and had frequent bronchial obstructive reactions and seizures that destabilized him, resulting in an extensive and severe neurological injury. Medical evidence indicated, with a high degree of certainty, that if Ramon survived, he would be quadriplegic (total loss of use of all four limbs) and have severe cognitive impairment. In this context, physicians, nurses and parents agreed that life support was against Ramón's best interest because such measures (need for a continuous IV line, airway aspiration, sedatives and, sometimes, even paralytic drugs) only caused additional suffering and no benefits for the patient, prolonged suffering and implied an extremely low quality of life, and that providing life support only for the purpose of alleviating the pain of losing a child was against Ramón's own dignity. Therefore, one morning, with Ramón in his mothers' arms and next to his father, he was taken off mechanical ventilation. Sedatives were increased to manage a potential sensation of shortness of breath. Few minutes later Ramón had an apnea episode, which resulted in a cardiac arrest, and died; resuscitation was not attempted.

\section{Case 3. Persistent vegetative state}

Pedro, a 15-year-old boy, was in a car crash and suffered a brain injury which left him in a vegetative state. He was intubated and on mechanical ventilation for more than 17 months and never regained consciousness nor had any reaction to or interaction with the outside world. His parents asked for the endotracheal tube to be removed and to let him die in peace. Knowing Pedro, they assured that this was what their son would have wanted. Physicians removed the endotracheal tube that was connected to the ventilator and Pedro died approximately 30 minutes later.. 
and has no consciousness, but a sleep-wake cycle is present, and the patient is capable of making automatic gestures (smiling, wincing, etc.) but there is no recognizable relation to stimuli.

Table 1 is a transcription of the three hypothetical case histories included in the survey.

Parts identified as " $\mathrm{B}$ " and " $\mathrm{C}$ " provide ample space for respondents to delve into their concepts and opinions.

The study population included all judges, defenders, and prosecutors from criminal and civil justice and oral trial courts, defenders and advocates of minors and legally incompetent persons from criminal and civil justice, and forensic physicians. Only personnel from the National Judiciary and the Guardianship Office who might intervene in cases of WLS in children were included. Survey respondents signed

TABLE 2. Description of survey respondents (n: 68)

\begin{tabular}{|c|c|}
\hline Demographic data & Percentage (n) \\
\hline $\begin{array}{l}\text { Older than } 50 \text { years old } \\
\text { Male } \\
\text { Married } \\
\text { With children }\end{array}$ & $\begin{array}{l}70 \%(35 ; 18 \text { did not answer }) \\
73.53 \%(49 ; 1 \text { did not answer) } \\
67.31 \% \text { ( } 35 ; 17 \text { did not answer) } \\
82.35 \% \text { (43; } 17 \text { did not answer) }\end{array}$ \\
\hline $\begin{array}{l}\text { Religion } \\
\text { Catholic } \\
\text { Atheist or agnostic } \\
\text { Jew and other religions } \\
\text { Did not answer }\end{array}$ & $\begin{array}{l}72.54 \%(37) \\
23.52 \%(12) \\
3.92 \%(2) \\
17\end{array}$ \\
\hline $\begin{array}{l}\text { Religious practice } \\
\text { Never } \\
\text { Seldom } \\
\text { Regularly } \\
\text { Did not answer }\end{array}$ & $\begin{array}{l}45.8 \%(22) \\
35.4 \%(17) \\
18.8 \%(9) \\
20\end{array}$ \\
\hline $\begin{array}{l}\text { Profession } \\
\text { Lawyer } \\
\text { Physician } \\
\text { Dentist/Psychologist }\end{array}$ & $\begin{array}{l}73.53 \%(50) \\
23.53 \%(16) \\
2.94 \%(2)\end{array}$ \\
\hline $\begin{array}{l}\text { Professional experience } \\
20 \text { or more years } \\
\text { Did not answer }\end{array}$ & $\begin{array}{l}84 \%(42) \\
18\end{array}$ \\
\hline $\begin{array}{l}\text { Position } \\
\text { Expert } \\
\text { Judge } \\
\text { Criminal defense lawyer } \\
\text { Prosecutor } \\
\text { Defender of minors and le } \\
\text { incompetent persons } \\
\text { Guardianship advisor }\end{array}$ & $\begin{array}{l}26.27 \%(18) \\
48.53 \%(33) \\
17.65 \%(12) \\
1.47 \%(1) \\
11 y \\
4.41 \%(3) \\
1.47 \%(1)\end{array}$ \\
\hline $\begin{array}{l}\text { Training } \\
\text { Graduate } \\
\text { Post-graduate } \\
\text { Doctoral program }\end{array}$ & $\begin{array}{l}39.70 \%(27) \\
47.05 \%(32) \\
13.23 \%(9)\end{array}$ \\
\hline
\end{tabular}

Percentages were estimated leaving out items that were not answered. a written informed consent, and the study was approved by the Ethics Committee and the Institutional Review Board of Hospital de Pediatría "Prof. Dr. Juan P. Garrahan", and the Health Research Committee (Comision Nacional Salud Investiga) of the National Ministry of Health.

For descriptive statistics purposes, categorical outcome measures were described as proportion and $95 \%$ confidence interval (95\% CI). The univariate analysis was done using the $\chi^{2}$ test. No multivariate analysis was done due to the small $n$ size $(n=51)$. Answers were qualified by two principal investigators separately, and differences were solved by consensus. Data were analyzed using the Stata 9.0 statistical package for Windows (StataCorp, College Station, Texas, USA).

\section{RESULTS}

Between April and August 2011, 185 surveys were distributed: 135 among National Judiciary members and 50 among members of the Forensic and Legal Medicine Board. Sixty-eight (36.76\%) surveys were returned: 50 from the National Judiciary and 18 from Forensic and Legal Medicine Board. Among these 68 surveys, 17 (25\%) members of the National Judiciary did not complete section " $\mathrm{C}$ ": 7 criminal defense lawyers and 10 judges.

Descriptive data of survey respondents are shown in detail in Table 2.

Most respondents (47: 92.15\%) were never involved in a WLS case. To $96.15 \%$ of respondents (50 out of 52 completed surveys), "killing someone", "helping someone to die" and "allowing someone to die" were not the same.

Among the 50 respondents who answered the section about withholding treatment versus interrupting or withdrawing treatment, $84 \%$ (42) considered that these were legally separate entities while $16 \%$ (8) considered both situations were legally equivalent.

\section{Analysis of hypothetical case histories}

This section of the survey was completed by 48-51 respondents. Seventeen respondents systematically omitted this section because the National Chamber of Civil Appeals forbade judges from the civil courts from participating in the survey by alleging that they might eventually fall under prejudice should they become involved in a future case.

Table 3 is a summary of answers given to each case. Among respondents who completed this 
section, for case $1,30 \%$ criminalized the measures taken; for case 2, $41 \%$; and for case $3,39 \%$.

Table 4 describes the type of crime attributed to each case.

\section{Pooled analysis of the three case histories}

In the pooled analysis of answers regarding the three cases, it was observed that 28 (55\%) respondents did not criminalize any of the decisions made. On the contrary, 13 (25\%) respondents considered that actions taken in all three cases constituted a crime; $6(12 \%)$ criminalized one of the three cases; and $4(8 \%)$ criminalized two out of the three.

Among the answers provided for the three case histories, $73.81 \%(n=110)$ agreed on the withdrawal of MV. Also, $63.40 \%(n=97)$ focused on the need to have these situations resolved in the health care setting, without the need of requesting legal authorization. In terms of variation in the opinions regarding the existence of advance medical directives (AMD) or when the patient was an adult, most respondents did not modify their answer: $116(76.8 \%)$ and $115(77.2 \%)$ of answers, respectively.

Actions described in the case histories were identified with euthanasia by $47 \%(\mathrm{n}=24)$ of respondents. In this regard, case 2 was mostly considered this way $(23 \%, 11$ respondents), followed by case 3 (19.6\%, 9 respondents). Case 1 was the one with fewer references to euthanasia ( $8 \%, 4$ respondents).

TABLE 3. Answers from respondents regarding each hypothetical case

\begin{tabular}{lccc}
\hline & Case 1 n (\%)* & Case 2 n (\%) $^{*}$ Case 3 n (\%)* $^{*}$ \\
\hline In general, agree with decisions made. & $45 / 51(88.23 \%)$ & $33 / 43(76.74 \%)$ & $36 / 50(72 \%)$ \\
Decisions made did not constitute a crime. & $35 / 50(70 \%)$ & $29 / 49(59 \%)$ & $28 / 46(61 \%)$ \\
Agree with no CPR. & $39 / 49(79.59 \%)$ & - & - \\
Agree with withdrawing MV. & $39 / 50(78 \%)$ & $36 / 50(72 \%)$ & $35 / 49(71.42 \%)$ \\
Would not change their answer even if the patient had an AMD. & $40 / 51(78.43 \%)$ & $41 / 51(80.39 \%)$ & $35 / 49(71.43 \%)$ \\
Would not change their answer if the patient was an adult. & $39 / 51(76.47 \%)$ & $41 / 50(82 \%)$ & $35 / 48(72.92 \%)$ \\
It is not necessary to request a legal authorization for WLS. & $35 / 51(68.63 \%)$ & $31 / 51(60.78 \%)$ & $31 / 51(60.78 \%)$ \\
Do not agree with withdrawing parenteral hydration or feeding. & - & - & $32 / 49(65.31 \%)$ \\
Do not agree with withdrawing enteral hydration or feeding. & - & - & $32 / 51(62.74 \%)$ \\
\hline
\end{tabular}

* $\mathrm{n}=$ answers/respondents who answered the item.

CPR: cardiopulmonary resuscitation; MV: mechanical ventilation; AMD: advance medical directive;

WLS: withholding/withdrawing of life support.

TABLE 4. Types of crimes attributed in each case

\begin{tabular}{lcccccc}
\hline & \multicolumn{2}{c}{ Case 1 } & \multicolumn{2}{c}{ Case 2 } & \multicolumn{2}{c}{ Case 3 } \\
& $\mathbf{n}$ & $\mathbf{\%}$ & $\mathbf{n}$ & $\mathbf{\%}$ & $\mathbf{n}$ & $\mathbf{\%}$ \\
\hline Intentional homicide & 4 & 8 & 11 & 23 & 9 & 19.6 \\
Wrongful death & 5 & 10 & 3 & 6 & 4 & 8.7 \\
Failure to render assistance & 2 & 4 & 3 & 6 & 2 & 4.3 \\
Inciting a person to commit suicide & 0 & 0 & 0 & 0 & 0 & 0 \\
Several crimes* & 4 & 8 & 3 & 6 & 3 & 6.5 \\
No crime & 35 & 70 & 29 & 59 & 28 & 61 \\
Total & 50 & 100 & 49 & 100 & 46 & 100 \\
\hline
\end{tabular}

* Several combinations of the four crimes listed here.

TABLE 5. Determination of crime probability based on original profession

\begin{tabular}{lcccc}
\hline $\begin{array}{l}\text { Type of } \\
\text { profession }\end{array}$ & $\begin{array}{c}\text { No case constituted } \\
\text { a crime }\end{array}$ & $\begin{array}{c}\text { One case constituted } \\
\text { a crime }\end{array}$ & $\begin{array}{c}\text { Total for the type } \\
\text { of profession }\end{array}$ & “Risk" rate \\
\hline Legal $^{1}$ & 15 & 20 & 35 & $57.1 \%$ \\
Health care $^{2}$ & 13 & 3 & 16 & $18.7 \%$ \\
Total cases by crime yes/no & 28 & 23 & 51 & $45.1 \%$ \\
\hline
\end{tabular}

${ }^{1}$ Attorneys, including judges, prosecutors, defenders, a scribe, etc.

${ }^{2}$ Health care, including physicians, a psychologist, and a dentist.

Odds ratio 5.7 (95\% CI: 1.4-24), p= 0.024 (Fisher's exact test). 
No differences were observed in opinions in terms of religion, sex or profession (judges, prosecutors, and defenders). A significant association was observed between working in the legal field and a higher likelihood of criminalizing any of the three cases, compared to health care providers, which included physicians, a psychologist and a dentist (Table 5). On the contrary, religion (grouped by Jewish-Christian tradition or agnostic-atheist) was not associated with differences in the criminalization of decisions made $(p=0.9)$.

\section{Qualitative results}

Handwritten comments and notes made by survey respondents and the subjective findings resulting from personal interviews with respondents are available in the supplementary material (Annex).

\section{DISCUSSION}

WLS is a common decision made in pediatric intensive care units (PICUs) across the world ${ }^{2-13}$ and in Argentina, ${ }^{14}$ and, to this date, no court claims have been made in Argentina in relation to WLS.

However, the "fear of litigation"* is a factor that may have a negative impact on decisionmaking processes, communication with the patient's family, and their duly participation in such decisions.

Actually, the fear of litigation may result, on the one side, in therapeutic obstinacy ${ }^{15-20}$ and, on the other, in an inadequate WLS. ${ }^{17,18,21}$ It may also affect the level of communication ${ }^{22,23}$ and inquiry on WLS decisions with the family.

It may be believed that the existence of bioethical, medical and legal grounds and the absence, in Argentina, of court decisions against WLS does not justify such fears. However, this study explores, for the first time in our country, legal workers' opinions in relation to WLS and shows that health care providers' fear of litigation may be justified.

\footnotetext{
*We refer to "fear of litigation" as the psychological "driving force" of "defensive medicine", a MESH and DeCS term defined as "alterations of modes of medical practice, induced by the threat of liability, for the principal purposes of forestalling lawsuits by patients". (http:/ / pesquisa.bvsalud. org / portal/decs-locator/ ?lang=es\&tree_id=I01.880.604. 583.524.300\&term $=\mathrm{I} 01.880 .604 .583 .524 .300$. Accessed on: December 2014).
}

Although, as expected, most respondents agreed with the decisions made in the hypothetical case histories, a remarkable number of them (45\%) found one or more crimes in a setting that, as presumed by authors, posed an ethically and legally valid case of WLS, similar to those commonly observed in Argentine PICUs. ${ }^{14,15,24,25}$

It is striking that justice workers, regardless of their position (judge, prosecutor, defender, or advocate of minors), had such dissimilar opinions regarding medical practice in its legal significance, both in relation to the "crime-no crime" dilemma and the type of crime (intentional homicide or wrongful death, failure to render assistance, or inciting a person to commit suicide), to the point that, for the same case, both a homicide and the non-existence of a crime were proposed. Or the fact that the same practice may be criminalized as any of the four criminal definitions indistinctly.

It was obvious, during the conduct of the survey and based on respondents' comments, that contact with real cases of severely ill patients who have no reasonable possibilities of recovery or improvement in the setting of tertiary pediatric practice had made these legal workers upset. The distress caused by these situations became evident during interviews. Respondents made an effort to provide, on the one side, a "technical and professional" opinion, but on the other side, they had an understanding, empathetic and compassionate position regarding others' pain. In their effort to achieve a balance, when they believed that the case constituted a crime, from a technical point of view, they also attempted to "overturn" the legal perspective and find a legal framework that would reduce the sentence, exclude illegality or prevent accountability.

It is also worth noting, as a positive finding, that many survey respondents $(63.40 \%)$ stressed the need for these matters to be resolved in the health care setting and that, if a third party was required to intervene other than $-\mathrm{a}$ the treating team or the patient and his/her family, they proposed the participation of an ethics committee and avoiding judicialization of the health care relationship.

We agree with this consideration. It is understandable that judicial involvement should be an exceptional resource, the last resort once all possibilities of agreement with the patient and his/her family regarding the management plan have been exhausted. In this regard, the role of the ethics committee is essential because it allows understanding the health-disease situation 
from different scientific and lay perspectives. As a matter of principle, and supported on survey findings, the participation of an ethics committee should be requested if discrepancies, questionings, and/or doubts arose regarding the medical decision-making process. Only if discrepancies are against the patient's best interest and an ethics committee is not able to establish consensus, it would be acceptable to make a legal claim.

Another remarkable finding of this study was that most respondents $(73.81 \%)$ agreed to the withdrawal of MV in the three cases, which has been frequently problematic given that, although not initiating and withdrawing life support have been considered ethically and legally equivalent, ${ }^{1,26-29}$ for the health care team it is morally more challenging to interrupt a treatment than to withhold it. Health care providers tend to give a different psychological/emotional significance to withholding treatment versus withdrawing it. ${ }^{30}$ The latter is usually not easily accepted among health team members, mostly because the proximity of the patient's death following interruption makes them feel like they are "causing" their death, even if that is not their intention.

Given that this is an original study, there are no previous references for comparing results, but it is worth noting its significant limitations. First of all, the low response rate, especially regarding the most important section of the survey: hypothetical case histories. The $27 \%$ response rate hinders the possibility of generalizing results. However, $45 \%$ of survey respondents believed that one, two or the three cases were related to some form of crime. Even if those who did not complete the survey had indicated that they did not typify any crime in any of the hypothetical cases -a highly unlikely polarization of opinions$12 \%$ of respondents would still criminalize decisions made.

Secondly, the survey technique may not have been sufficient to convey such complex medical concepts and situations in an effective manner to non-medical professionals. However, respondents indicated that they were cognitively -although not emotionally- comfortable with case description and, even though this was a self-administered survey, the investigator was available to discuss and clarify any aspect that might have arisen while reading it.

Thirdly, the survey was administered before the modification in the National Patient's Rights
Law, medically referred to as the "Death with Dignity Law" (May 2012), which has definitely helped to modify the general attitude regarding these situations.

However, there are data supporting the prevalence of this issue. For example, the case of Marcelo Diez, an adult patient who has been in a persistent vegetative state for the past 20 years. His family has made a claim for the withdrawal of life support. An expert report by the National Forensic and Legal Medicine Board and three opinions issued by bioethics committees (Committee for the Provincial Board of Management Quality of the Secretariat of Health of Neuquén, Ethics Committee of the Argentine Society of Intensive Care, and Ethics Committee of INCUCAI ${ }^{\dagger}$ ) support the family's request. At present, the case has been raised to the Supreme Court because, after having been in the hands of 15 members of the National Judiciary, including different court judges, the Attorney General, etc., and even after the above-mentioned law was passed, WLS has not been authorized. We believe this case is far from being resolved.

The fear of litigation that many health care providers have at the time of making end-of-life decisions regarding their patients' lives may be justified. We believe that new comprehensive clinical practice guidelines, which provide details regarding the decision-making process, as those published in other countries, ${ }^{31-33}$ developed by health care providers, legal professionals, and bioethicists will help to improve the quality of care provided to patients, their families and the health team.

\section{CONCLUSION}

Forty-five percent of survey respondents considered that decisions made constituted some form of crime, and this opinion was significantly associated with working in the legal field compared to working in the health care setting. In addition, variations in the type of crime considered were also observed.

\section{REFERENCES}

1. RoyalCollege of Paediatrics and Child Health. Withholding or withdrawing life saving treatment in children: a framework for practice. 2nd ed. London: Royal College of Paediatrics and Child Health; 2004. Pages 10-1 and 28-9.

\footnotetext{
** Instituto Nacional Central Único Coordinador de Ablación e Implante.
} 
2. Mink RB, Pollack MM. Resuscitation and withdrawal of therapy in pediatric intensive care. Pediatrics 1992;89(5): 961-3.

3. Vernon DD, Dean JM, Timmons OD, Banner W Jr, et al. Modes of death in the pediatric intensive care unit: withdrawal and limitation of supportive care. crit care Med 1993;21(11):1798-802.

4. Lantos JD, Berger AC,Zucker AR. Do-not-resuscitate orders in a children's hospital. crit care Med 1993;21(1):52-5.

5. Martinot A, Lejeune C, Beyaert C, Hue V, et al. Modes of death in a French pediatric intensive care unit (PICU). Proc Eur Soc Pediatr Intensive Care 1994;A20.

6. Burns JP, Mitchell C, Outwater KM, Geller M, et al. End-oflife care in the pediatric intensive care unit after the forgoing of life-sustaining treatment. Crit Care Med 2000;28(8):3060-6.

7. Devictor DJ, Nguyen DT. Forgoing life-sustaining treatments: how the decision is made in French pediatric intensive care units. Crit Care Med 2001;29(7):1356-9.

8. Garros D, Rosychuk RJ, Cox PN. Circumstances surrounding end of life in a pediatric intensive care unit. Pediatrics 2003;112(5):e371.

9. Devictor DJ, Nguyen DT. Forgoing life-sustaining treatments in children: a comparison between Northern and Southern European pediatric intensive care units. Pediatr crit care Med 2004;5(3):211-5.

10. Zawistowski CA, DeVita MA. A descriptive study of children dying in the pediatric intensive care unit after withdrawal of life sustaining treatment. Pediatr Crit Care Med 2004;5(3):216-23.

11. Kipper DJ, Piva JP, Garcia PC, Einloft PR, et al. Evolution of the medical practices and modes of death on pediatric intensive care units in southern Brazil. Pediatr Crit Care Med 2005;6(3):258-63.

12. Cuttini M, Nadai M, Kaminski M, Hansen G, et al. End-oflife decisions in neonatal intensive care: physicians' selfreported practices in seven European countries. EURONIC Study Group. Lancet 2000;355(9221):2112-8.

13. Lago PM, Devictor D, Piva JP, Bergounioux J. End-oflife care in children: the Brazilian and the international perspectives. J Pediatr (Rio J) 2007;83(2 Suppl):S109-16.

14. Althabe M,Cardigni G, Vassallo JC, AllendeD, et al. Dying in the intensive care unit: collaborative multicenter study about forgoing life-sustaining treatment in Argentine pediatric intensive care units. Pediatr Crit Care Med 2003;4(2):164-9.

15. Comité de Ética Hospitalaria Hospital de Pediatría "Prof. Dr. J.P. Garrahan". Recomendaciones para la toma de decisiones terapéuticas en pacientes gravemente enfermos. Arch Argent Pediatr 1998;96(6):399-403.

16. Ballard DW, LiY, Evans J, Ballard RA, et al. Fear of litigation may increase resuscitation of infants born near the limits of viability. J Pediatr 2002;140(6):713-8.

17. Perkins HS, Bauer RL, Hazuda HP, Schoolfield JD. Impact of legal liability, family wishes, and other "external factors" on physicians' life-support decisions. Am J Med 1990; 89(2): 185-94.

18. Bell C, Somogyi-Zalud E, Masaki K, Fortaleza-Dawson T, et al. Factors associated with physician decision-making in starting tube feeding. J Palliat Med 2008;11(6):915-24.
19. Piva J, Lago P, Othero J, Garcia PC, et al. Evaluating end of life practices in ten Brazilian paediatric and adult intensive care units. J Med Ethics 2010;36(6):344-8.

20. Soares M, Terzi RG, Piva JP. End-of-life care in Brazil. Intensive care Med 2007;33(6):1014-7.

21. Garcia-Retamero R, Galesic M. On defensive decision making: how doctors make decisions for their patients. Health Expect 2014;17(5):664-9.

22. Asher E, Greenberg-Dotan S, Halevy J, Glick S, et al. Defensive medicine in Israel. A nationwide survey. PLoS One 2012;7(8):e42613.

23. Belizan M, Meier A, Althabe F, Codazzi A, et al. Facilitators and barriers to adoption of evidence-based perinatal care in Latin American hospitals: a qualitative study. Health Educ Res 2007;22(6):839-53.

24. Ghiggi M, Chede C, Saporiti A. De lo que no se habla en la UCIP. Arch Argent Pediatr 2001;99(4):337-9.

25. Ciruzzi MS. La limitación de soporte vital: ¿Derecho, Deber o Delito? [Internet]. [Accessed on: March 24, 2015]. Available at: http:/ / www.unesco.org.uy/shs/fileadmin/ templates/shs/archivos/TrabajosLibres-Bioetica/ 24.\%20 La\%20lmitacion\%20de\%20Soporte\%20vital.pdf.

26. Comité Nacional de Terapia Intensiva Pediátrica. Consenso sobre recomendaciones acerca de la limitación del soporte vital en terapia intensiva. Arch Argent Pediatr 1999;97(6): 411-5.

27. American Academy of Pediatrics Committee on Bioethics: Guidelines on foregoing life-sustaining medical treatment. Pediatrics 1994;93(3):532-6.

28. Monzón Marín JL, Saralegui Reta I, Abizanda I Campos $\mathrm{R}$, Cabré Pericas L, et al. Recomendaciones de tratamiento al final de la vida del paciente crítico. Med Intensiva 2008; 32(3):121-33.

29. Royal Australasian College of Physicians. Decision-Making at the End of Life in Infants, Children and Adolescents. Sidney: Royal Australasian College of Physicians; 2008. [Accessed on: April 1, 2015]. Available at: https://www. racp.edu.au/docs/default-source/advocacy-library / decision-making-at-the-end-of-life-in-infants-childrenand-adolescents.pdf?sfvrsn $=10$.

30. Althabe M,Ledesma F, Cernadas C, Flores C, etal. Actitudes de los profesionales de salud frente a las decisiones de limitación o retiro de tratamiento en pediatría. Arch Argent Pediatr 2003;101(2):85-92.

31. Berlinger N, Jennings B, Wolf SM. The Hastings Center Guidelines for Decisions on Life-Sustaining Treatment and Care Near the End of Life: Revised and Expanded Second Edition. New York: Oxford University Press; 2013.

32. Larcher V, Craig F, Bhogal K, Wilkinson D, et al. Making decisions to limit treatment in life-limiting and lifethreatening conditions in children: a framework for practice. Arch Dis child 2015;100(Suppl 2):s3-23.

33. Australian and New Zealand Intensive Care Society. ANZICS Statement on Care and Decision-Making at the End of Life for the Critically Ill. Edition 1.0. Melbourne: ANZICS; 2014. 


\section{ANNEX - QUALITATIVE ANALYSIS}

\section{Descriptive study regarding the opinions of members of the National Civil (Family Proceedings) and Criminal Courts in withholding or withdrawing of life support situations in pediatrics}

\section{Comments and/or notes made by survey respondents who indicated to have been involved in a case of withholding or withdrawing of life support}

Judge: "I was not involved as a legal worker, but personally. I had to make a decision, together with my family, regarding the 'dignified death' of that person".

Physician: "At the Neonatal Intensive Care Unit, I have been involved in the decision regarding critically-ill patients (congenital heart disease, sepsis, ventilatory failure) whose life functions and prognosis are unsustainable".

Physician: "Elderly, 84-year-old patient with brain death for more than 78 hours, multiple organ failure resulting from a hemorrhagic stroke. Life support was withdrawn".

Physician: "I had to authorize multiple organ procurement procedures due to brain death (two cases)".

\section{Comments and/or notes made by survey} respondents regarding the three cases in general

Appeal court judge: General note on the survey: "It might seem contradictory to strongly agree with and, at the same time, criminalize an action. Legalizing euthanasia, in all of its forms, is a debt of the legislative body. In my opinion, it is necessary to set the issue in the agenda. Considering physicians (generally working in public hospitals and caring for lowincome patients) have to request authorization to perform therapeutic (not punishable) abortions, they might face even more problems in these situations".

Appeal court judge: This judge indicated, in general, to agree with the decisions made in the three cases. Her general opinion was: "Every medical decision made in these hypothetical cases should be accompanied by a report of a bioethics committee".

Investigating judge: He refused to complete this section of the survey and indicated: "Taking this survey implies some sort of prejudice, delivering an opinion outside the case file".
Case 1. No chance situation

Comments and/or notes made by survey respondents regarding case 1

Level of agreement and presence/absence of a crime

Judge (who selected "In general, strongly agree with decisions made" and "No crime"): "To me it is clear. I share the parents' decision and the respect of the medical team for such decision. In the description of the case, I assume that parents also respected their child's will (at 11 years old a child is capable of communicating adequately). I recognize dominion over our own bodies. The single most important piece of information was what Mariela wanted. Argentina requires a regulation that, for adults, may allow for the establishment of a 'living will'".

Judge (who selected "In general, strongly agree with decisions made" and "No crime"): "Parents are representatives of their child's will. If the decision was not vitiated, it is absolutely mandatory from a legal perspective, so the moral stance becomes irrelevant, whether allegations are made for or against it. In addition, the decision should be duly documented".

Judge (who selected "In general, strongly agree with decisions made" and "No crime"): "Family consensus and the medical report based on the impossibility of the patient's survival given her irreversible, end-stage condition, together with the decision not to do anything that may result in death, allow assuming that such alleged withholding (cardiopulmonary resuscitation) was not the cause of such result. Based on this, I agree with the last choice in the survey".

Physician (who selected "In general, strongly agree with decisions made" and "No crime"): "Physicians are not trained for a patient's 'dignified death'... which is as or even more relevant than a 'dignified life', as in the case described here".

Physician (who selected "In general, strongly agree with decisions made" and "No crime"): "I believe that, in medical practice, it is necessary to deal with human omnipotence -that of the physician-, and this includes considering the family's opinion and collaborating to reach consensus, preserving the doctor-patient 
relationship and acknowledging the limits of practice. In my opinion, parents are finally the ones that should decide, within the realms of what is reasonable".

Physician (who selected "In general, strongly agree with decisions made" and "No crime"): "If the patient's situation is that of 'no reasonable chance of recovery' and the family agrees not to escalate life support, I believe it is right to let the institution 'decide' on the end and the time for it. Otherwise, it would be a matter of obstinacy and medical and financial(?) arrogance".

Physician (who selected "In general, somewhat agree with decisions made" and "Wrongful death"): "As per our Code, euthanasia is forbidden, so it would be a crime, even though it might be medically or clinically the most convenient thing to do".

Physician (who selected "In general, somewhat agree with decisions made" and "No crime"): "I guess that, if conditions permit, a submission should be made before the ethics committee to clearly establish (regardless of the patient's acute condition and severe multiple organ failure) whether she would have become a transplant candidate had she recovered from sepsis".

Physician (who selected "In general, strongly agree with decisions made" and "No crime"): "She had no chance at all; had the transplant been successful, who could warrant she would not have sequelae? Was it possible to ensure her an adequate quality of life?".

Physician (who selected "In general, strongly agree with decisions made" and "No crime"): "In these situations, physicians are also responsible for letting patients have a 'dignified death'. The limit of therapeutic obstinacy is that of alleviating physical pain. I have my reservations about family involvement in this decision. I have made such decision on my own several times".

Investigating judge (who selected "In general, strongly agree with decisions made" and "No crime"): "I would decide in accordance with legal provisions and the evidence presented in each specific case, after verifying there is really no possible treatment. Once every point in the case has been verified, there would be no crime".

Judge (who selected "In general, strongly agree with decisions made" and both "Wrongful death" and "No crime"): "If a treatment that is mandatory as per the standards of the art of healing (medical protocol) is withheld, such withholding may be considered a violation to the duty of providing medical care and the risk of death would be increased (wrongful death may be reported against physicians and parents, given that the latter act as guarantors for their child)".

Appeal court judge (who selected "In general, strongly agree with decisions made" and "Intentional homicide"): "Even though I strongly agree with the decision, as a judge, if I was asked to intervene in the case, I would consider different situations that may relieve [parties] from liability; however, from a strictly dogmatic stance, it is an intentional homicide by negligence".

Criminal defense lawyer (who selected "In general, disagree with decisions made" and both "Failure to render assistance" and "Inciting a person to commit suicide"): "A matter to consider would be what sentence would be more benign towards parents and physicians".

Investigating judge (who selected "In general, somewhat agree with decisions made" and "Intentional homicide"): "A cause for justification that rules out illegality or a cause that would relieve parties from liability. Although the case fits the definition of intentional homicide, I would always look for a justification or a cause that would relieve parties from liability: a necessity based on the case-specific circumstances".

Judge (who selected "In general, somewhat agree with decisions made" and "Failure to render assistance"): "Although this case may fit the crime punished by article 106 of the Criminal Code regarding the fact that a person unable to help herself was left to her fate, a person who should be cared for according to what was promised by physicians in the Hippocratic Oath, when faced by inevitable death, the decision to waive a treatment that would only prolong life in a precarious and arduous manner is legal. This is established in article 19 of Law 17132 regarding Medical Practice".

Investigating judge (who selected "In general, strongly agree with decisions made" and "Intentional homicide", "Wrongful death", "Failure to render assistance", and "Inciting a person to commit suicide"): "Causes for nonattributability should be considered. These are established in the Criminal Code: considering consent as a cause for justification".

Appeal court judge (who selected "In general, disagree with decisions made" and "Wrongful death"): "There are reasonable possibilities that go against an adequate legal decision regarding that there was no certain chance to continue with life. No end-stage prognosis was made". 
Degree of agreement with non cardiopulmonary resuscitation and withdrawal of mechanical ventilation

Judge (who selected "In general, strongly agree with decisions made" and "No crime"): "I would not change my decision if parents had consented to it".

Judge (who selected "In general, strongly agree with decisions made", "No crime" and "Would change my decision"): "The patient was 11 years old, so it is assumed her maturity was enough to face 'therapeutic obstinacy".

Judge (who selected "In general, strongly agree with decisions made", "No crime" and "Would not change my decision"): "Minors should be heard (Convention on the Rights of the Child); however, I value parents' opinion".

Physician (who selected "In general, strongly agree with decisions made", "No crime" and "Would change my decision"): "If there is no chance, i.e., no reasonable possibilities, as described in the case".

Physician (who selected "In general, strongly agree with decisions made", "No crime" and "Would not change my decision"): "The patient's decision should be respected, even if she was a minor".

Physician (who selected "In general, strongly agree with decisions made", "No crime" and "Would not change my decision"): "I do not believe autonomy should be considered, especially in terms of her age".

Physician (who selected "In general, strongly agree with decisions made", "No crime" and "Would not change my decision"): "Minors and mentally-disabled persons cannot give a valid consent. It would not change my opinion".

* Investigating judge (who selected "In general, strongly agree with decisions made", "No crime" and "Would not change my decision"): "It would not change my decision because she was a minor".

Judge (who selected "In general, strongly agree with decisions made", "Wrongful death", "No crime" and "Would not change my decision"): "I would not change my decision, I would simply consider the victim's consent, the autonomy of her will to decide".

Appeal court judge (who selected "In general, strongly agree with decisions made", "No crime" and "Would change my decision"): "Although the minor is considered incompetent, based on the Convention and Law 26061, she should be heard".

Judge (who selected "In general, strongly agree with decisions made", "No crime" and "Would change my decision"): "This is an 11-yearold minor so, as in every case, she should be considered as unable to understand what she is asking for or, on the contrary, for that reason, it is more valuable".

Oral trial court judge (who selected "In general, strongly agree with decisions made", "No crime" and "Would change my decision"): "I do not agree with withdrawing or withholding artificial feeding/hydration because it is a basic health care procedure, not simply a treatment. A minor patient may decide on his/her preferences, and parents should decide considering such preferences".

Investigating judge (who selected "In general, somewhat agree with decisions made", "Intentional homicide" and "Would change my answer"): "Every parental decision includes a selfish component. If the patient's will was documented, the decision made by parents is an act of greatness".

Judge (who selected "In general, somewhat agree with decisions made", "Failure to render assistance" and "Would not change my answer"): "In the case of minors, their parents' or guardians' consent is valid, although it may be replaced by a legal authorization".

Appeal court judge (who selected "In general, disagree with decisions made", "Wrongful death" and "Would change my decision"): "It is a matter of legal capacity".

\section{Change of opinion in the presence of advance medical directives or in the case of adult patients}

Judge (who selected "In general, strongly agree with decisions made", "No crime" and "Would not change my decision"): "Under the same conditions: ensure the decision was not vitiated and was duly documented".

Judge (who selected "In general, strongly agree with decisions made", "No crime" and "Would change my decision"): "As long as the girl was younger. If the patient was really young or there was no consensus among the three of them (father, mother, child)".

Judge (who selected "In general, strongly agree with decisions made", "No crime" and "Would change my decision"): "I believe that the will to have a dignified death is critical".

Physician (who selected "In general, somewhat agree with decisions made", "No crime" and "Would change my answer"): 
"Probably in relation to advance directives".

Physician (who selected "In general, strongly agree with decisions made", "No crime" and "Would not change my decision"): "A competent adult has a right to decide in these cases. I would ratify my decision and opinion on this subject".

Judge (who selected "In general, strongly agree with decisions made", "No crime" and "Would change my decision"): "It would clear all my doubts regarding the fact that it was adequate to withdraw treatment".

\section{It is necessary to request legal authorization}

Judge (who selected "In general, strongly agree with decisions made", "Wrongful death", "No crime" and "No need to require legal authorization"): "Medical science is suitable to make a diagnosis and establish the necessary procedures to manage the patient and decide what is right. Legal intervention would result in a delay and complications, worsening pain and distress for the family".

Judge (who selected "In general, disagree with decisions made", "Intentional homicide" and "No need to require legal intervention"): "Physicians are forced to provide care to patients and, given a severe condition, they should dispense with parental consent".

Oral trial court judge (who selected "In general, strongly agree with decisions made", "No crime" and "No need to require legal authorization"): "I believe ethics committees and institutional review boards should be trained to intervene in these conflicts and make recommendations. It is not up to judges to decide in these cases".

Criminal defense lawyer (who selected "In general, disagree with decisions made", "Failure to render assistance", "Inciting a person to commit suicide" and "No need to require legal intervention"): "If necessary, I would request a legal authorization. For legal protection of physicians and/or family members".

Investigating judge (who selected "In general, somewhat agree with decisions made", "Intentional homicide" and "No need to require legal intervention"): "I would ask for a legal authorization so that the judge acted as a supervisor to ensure that the rights of every party involved were respected. A control of legality".

Judge (who selected "In general, somewhat agree with decisions made", "Failure to render assistance" and "No need to require legal intervention"): "A civil judge should be asked to provide an authorization only if parents had discrepancies or did not agree, but not if both the family and physicians consent to the decision".

Investigating judge (who selected "In general, somewhat agree with decisions made", "Intentional homicide" and "Need to require legal intervention"): "Eventually, the sentence may be reduced, but that would not change anything about the fact that it is a crime".

\section{Subjective findings}

As per the individual appreciation of some survey respondents, the reference to "a situation with no reasonable chances of recovery" led them to believe that there was not sufficient certainty to justify the withholding of resuscitation.

Comments were a relevant tool: judges, in general, focused on autonomy, the patient's will and the decision-making process by parents in the name of their children. On their side, physicians recognized that they were not trained to deal with dignified death and how to accept the family's opinion and collaborate with them. One of the physicians even stated "his doubts" regarding the family's right to intervene in the decisionmaking process and acknowledged that he had taken the responsibility himself and many times had made the decision on his own. Another physician, who considered this was a case of euthanasia (i.e., intentional homicide), admitted that, from a medical or clinical perspective, to withhold or withdraw treatment would be the most convenient decision.

When asked to comment whether an advance medical directive would influence on their decisions, it was observed that judges were more willing to agree with the minor's autonomy and the decisions made by her parents. This was not the case of physicians, who considered that minors and mentally-disabled persons were not capable of giving their valid consent.

Most $(76.47 \%)$ would not change their answer if the patient was an adult. At this point, judges maintained their opinion regarding the autonomy of decisions (regardless of whether the patient was a minor or an adult); physicians considered that a capable adult patient had a right to decide in these cases.

In view of these results, it called our attention that physicians shared the medical decisions made in this first hypothetical case, and that they would have made them regardless of the will of both the parents and the girl (because they considered that she was not capable of giving 
her own consent). It seems like, to them, medical practice itself legalized the decision-making process, regardless of patient involvement. Also among physicians, in general, confusion was observed regarding the difference between legal capacity and bioethics competence.

\section{Case 2. Unbearable or poor quality of life situation \\ Comments and/or notes made by survey respondents regarding case 2}

Level of agreement and presence/absence of a crime

Judge (who selected "In general, strongly agree with decisions made" and "Intentional homicide"): "The actions may be painful, but they are justified. In this case, I believe the situation should be considered from the criminal theory perspective. If actions were justified, there is no need to look for a guilty party given that it would be authorized in our legal setting".

Judge (who selected "In general, strongly agree with decisions made" and "No crime"): "This is similar to case 1 , but the minor patient in this case cannot voice his opinion. If death is considered to be a brief instant, several adverse opinions are bound to arise. If death is understood as an irreversible process, I strongly agree with the decisions made in this case".

Judge (who selected "In general, disagree with decisions made" and "Intentional homicide"): "Agreement regarding ambiguous moral guidelines expressed as 'best interest' or 'dignity', in this case, is not enough to infer (deduce) consent. For such consent to have legal relevance, it should be signed, explained and duly documented. Lack of consent implies a presumption against the medical team: in this case, the only 'decision' made was not to document 'agreement'; this constitutes the basis for analysis and cannot be avoided by legal workers. The absence of a signed agreement enables a criminal investigation regarding the intentional homicide hypothesis".

Physician (who selected "In general, somewhat agree with decisions made" but did not complete the section regarding crime typification): "If technological prolongation of life only extends a fateful end (case 1), I would not even doubt about withdrawing all life support. If prolongation of life support ensures survival, I would not be capable, as a physician, to withdraw any technological life support provided to the child. I guess I would ask the hospital's ethics committee for an opinion".
Physician (who selected "In general, strongly agree with decisions made" and "No crime"): "Withholding life support parameters and preventing an additional suffering that may only result in a human being having a poor development and a very poor quality of life may be considered an act of euthanasia, in the good sense, even benevolence in this case. Likewise, I think the final decision should always be agreed upon with parents and managed reasonably, humanely and with common sense".

Physician (who selected "In general, strongly agree with decisions made" and "No crime"): "In the past, when such unproductive therapeuticinstrumental paraphernalia (at least in the cases described here) did not exist and death occurred 'naturally', refraining from acting was considered a crime. Life support should be restricted only to cases for which it is considered medically favorable or when the cause of life support requirement is potentially reversible".

Physician (who selected "In general, disagree/somewhat with decisions made" and both "Intentional homicide" and "No crime"): "Decisions should be made in accordance with present regulations, and all parties involved should participate (parents, physicians, etc.)".

Physician (who selected "In general, strongly agree with decisions made" and "No crime"): "What benefit were they looking for? What about his suffering due to shortness of breath and his parents' distress? This is an example of therapeutic obstinacy".

Physician (who selected "In general, strongly agree with decisions made" and "No crime"): "My comment regarding case 1 is also valid here. Insisting on life support, in these cases, means refusing the possibility of a dignified death".

Investigating judge (who selected "In general, strongly agree with decisions made" and "No crime"): "I would decide in accordance with legal provisions and the evidence presented in each specific case, after verifying there is really no possible treatment. Once every point in the case has been verified, there would be no crime".

Judge (who selected "In general, strongly agree with decisions made" and "No crime"): "My comment is the same as for case 1. If the procedure withheld here was mandatory as per the medical protocol and necessary (typical) to reduce the risk of death, the case may be reported as wrongful death. Otherwise, there is no crime here: physicians are not liable -based on their protocols- to become life-saving heroes beyond 
what is commonly adequate in each case".

Appeal court judge (who selected "In general, strongly agree with decisions made" and "Intentional homicide"): "Even though I strongly agree with the decision, as a judge, if I was asked to intervene in the case, I would consider different situations that may relieve parties from liability; however, from a strictly dogmatic stance, it is an intentional homicide by negligence".

Judge (who selected "In general, disagree with decisions made" and "Intentional homicide"): "Personally, I would do the same, whether I was the mother or the physician. However, if this case was brought to my court, I would not be able to avoid the intentional homicide charge".

Criminal defense lawyer (who selected "In general, disagree with decisions made" and "Failure to render assistance" and "Inciting a person to commit suicide"): "A matter to consider would be what sentence would be more benign towards parents and physicians".

Investigating judge (who selected "In general, strongly agree with decisions made" and "Intentional homicide"): "A cause for justification that rules out illegality or a cause that would relieve parties from liability. Although the case fits the definition of intentional homicide, I would always look for a justification or a cause that would relieve parties from liability: a necessity based on the case-specific circumstances".

Judge (who selected "In general, somewhat agree with decisions made" and "Failure to render assistance"): "As in case 1, and although the actions described fit into the punishment provided for in article 106, National Law 17132 establishes that, in the case of a disabled person, health care providers should ask for the consent of that person's representative regarding the refusal to receive treatment. The benevolence principle established in the Hippocratic Oath is limited by the patient's autonomy principle and, in theory, the will of those who have a protected legal right prevails. These bioethics principles and regulations were introduced in the first conference held in the USA (Kennedy Institute of Ethics). It is worth noting that, given that this patient is a minor, his parents' consent is essential; the medical team may not agree with their decision and request for a legal ruling against it".

Investigating judge (who selected "In general, disagree with decisions made" and "Intentional homicide"): "This crime is worsened because his parents are committing it and may be mitigated by an allegation of violent emotion".
Investigating judge (who selected "In general, strongly agree with decisions made" and "Intentional homicide"): "Mitigation might be implemented: criminal theory; exculpatory factors: prohibition mistake or a different behavior cannot be required".

Appeal court judge (who selected "In general, somewhat agree with decisions made" and "Intentional homicide"): "It may be categorized as manslaughter".

Investigating judge (who selected "In general, strongly agree with decisions made" and "Intentional homicide", "Wrongful death", "Failure to render assistance", and "Inciting a person to commit suicide"): "It may fit in this definitions technically".

Degree of agreement with no cardiopulmonary resuscitation, withdrawal of mechanical ventilation and change of opinion in the presence of advance medical directives

Physician (who selected "In general, strongly agree with decisions made", "No crime" and "Would not change my decision"): "Pediatric patients should always be heard and have a chance to voice their opinion if their condition allows them to do so".

Judge (who selected "In general, strongly agree with decisions made", "No crime" and "Would change my decision"): "As I commented for case 1, I would also ask for a consent document, and respect the patient's autonomy, will and freedom".

Appeal court judge (who selected "In general, strongly agree with decisions made", "Intentional homicide" and "Would not change my decision"): "Given that there is no law to support the decision, it would be difficult to obtain a different ruling".

Oral trial court judge (who selected "In general, somewhat agree with decisions made", "No crime" and "Would change my decision"): "I do not agree with withdrawing or withholding feeding and hydration".

Investigating judge (who selected "In general, strongly agree with decisions made", "No crime" and "Would change my decision"): "Every parental decision includes a selfish component. If the patient's will was documented, the decision made by parents is an act of greatness".

Change of opinion in the case of adult patients

Judge (who selected "In general, disagree with decisions made", "Intentional homicide" 
and "Would not change my answer"): "Except the 'agreements' made with the patient were documented regarding how unproductive and cruel treatments to be used are".

Oral trial court judge (who selected "Somewhat agree with decisions made", "No crime typified" and "Would change my answer"): "I do not agree with withdrawing or withholding feeding and hydration".

Criminal defense lawyer (who selected "Disagree with decisions made", "Typified as failure to render assistance", "Inciting a person to commit suicide" and "Would change my answer"): "In the case of an adult, he/she may decide what to do with his/her life".

Judge (who selected "Strongly agree with decisions made", "Typified as failure to render assistance" and "Would change my answer"): "In the case of an adult who has not signed a consent document, his family's consent should be requested".

\section{It is necessary to request legal authorization}

Judge (who selected "Strongly agree with decisions made", "Typified as wrongful death", "No crime typified" and "No need to require legal authorization"): "Medical science is suitable to make a diagnosis and establish the necessary procedures to manage the patient and decide what is right. Legal intervention would result in a delay and complications, worsening pain and distress for the family".

Appeal court judge (who selected "Strongly agree with decisions made", "Typified as intentional homicide" and "A judge cannot authorize it"): "Physicians should know the protocol to follow".

Oral trial court judge (who selected "Somewhat agree with decisions made", "No crime typified" and "No need to require legal authorization"): "I would recommend palliative care, care for a dignified death accompanied with emotional support, community support, an understanding of suffering, and an effective pain management".

Judge (who selected "Somewhat agree with decisions made", "No crime typified" and "It is necessary to require legal authorization"): "Even if the medical team and the patient's family had given their consent, I think it would be convenient to request a legal authorization".

\section{Subjective findings}

Analyzing opinions by profession, judges in general focused on the theory of crime and many times considered that decisions were illegal (i.e. forbidden) but justified (either based on the patient's consent or a clinical indication). One judge focused on the fact that the agreement to withhold life support made between the medical team and the family had not been documented and, in his opinion, this implied a presumption against the treating medical team and the corresponding legal investigation. On their side, physicians focused on the poor quality of life and the scarce chance of improvement; they considered that technology use was not warranted and prolonged suffering, and highlighted that it would be a case of therapeutic obstinacy.

A large number $(23.26 \%)$ of survey respondents disagreed with decisions made; and some of those who agreed $(15.52 \%)$ considered that the case may be criminalized (intentional homicide or wrongful death most of the times). This was reflected in some of the additional notes, which considered potential causes for sentence reduction or a justification for the crime (violent emotion, necessity, etc.).

The phrase "only prolonged suffering and implied an extremely low quality of life" raised concerns among respondents. Some believed that it was difficult to establish the level of quality of life while others thought it was not enough to end the child's life.

Off the record, during the interview, some judges considered that increasing the sedative dosage was the final action that caused the patient's death.

Although his underlying disease was relevant in his present condition, respondents who disagreed with decisions made considered that taking him off the ventilator was the "cause" of his death, with the resulting legal implications.

\section{Case 3. Persistent vegetative state Comments and/or notes made by survey respondents regarding case 3}

One judge refrained from commenting on this case because it raised concerns: "I will not comment on this case. I have doubts regarding the 'situation with no reasonable chances of recovery'. 'Reasonable' is a convention. Of course, the presence of advance directives would change my answer to the extent that they referred to this situation". 


\section{Level of agreement and presence/absence of a crime}

Judge (who selected "Somewhat agree with decisions made" and "No crime typified"): "I believe that the decisions made by parents, who are affected by the health situation of their most cherished gift -a child-, with the corresponding medical and therapeutic guidance cannot and should not be subjected to the opinion of a judge".

Judge (who selected "Disagree with decisions made" and refrained from commenting on the type of crime): "Before attempting to qualify the parents' behavior, which would be aggravated by their relationship with the victim and result in a life sentence, I would try to establish a different matter given the dramatic family situation. However, this case is different from the other two. I felt that parents were the ones who did not want to continue with their son in that condition. So I feel the need to look at this case from a different perspective; with the other two I had no doubts. If I had to rule in this case, I would not be able to make a linear ruling".

Prosecutor (who selected "Somewhat agree with decisions made" and refrained from commenting on the type of crime): "As far as I know, there have been uncommon cases of patients who awoke from a coma after years and recovered. I believe that in these cases the decision to withdraw mechanical ventilation and other artificial means of life support is more related to the family's interest in avoiding pain than the patient's best interest. Anyhow, I believe that if the patient dies following the withdrawal of life support, it does not constitute a crime. However, it would be a crime if the patient was breathing on his own and feeding and hydration were withheld".

Physician (who selected "Strongly agree with decisions made" and "No crime typified"): "In this case, I believe the parents' opinion is more relevant than in the other two. Anyhow, I believe these are borderline situations, hard to assess from the perspective of criminal codes. In these cases, physicians are the ones who stand up to the situation, and the main suffering is that of parents. For this reason, I believe these cases should not be brought to court, except they involve malpractice".

Physician (who selected "Somewhat agree with decisions made" and "Typified as failure to render assistance"): "In this case the withdrawal of mechanical ventilation is very difficult. Given the patient's age, I would consider he was autonomous (before the car crash) and, if he had advance directives, it might be all right to withhold ventilation in case of worsening of his condition, but if he needed it from the beginning, it would be a very difficult decision".

Physician (who selected "Strongly agree with decisions made" and "No crime typified"): "The case would fit the definition of persistent vegetative state, which is one of the clinical conditions that poses the possibility of withdrawing life support. The decision made is reasonable, even more if Pedro's opinion regarding the situation was known".

Investigating judge (who selected "Strongly agree with decisions made" and "No crime typified"): "I would decide in accordance with legal provisions and the evidence presented in each specific case, after verifying there is really no possible treatment. Once every point in the case has been verified, there would be no crime".

Judge (who selected "Strongly agree with decisions made" and "No crime typified"): "I think this case is like the other two. In this case, the risk of death was inevitable and the procedure was only delaying the result; it would not be reproachable because it neither caused nor increased the risk. It only caused it earlier and, according to some opinions, this does not constitute a crime".

Appeal court judge (who selected "Strongly agree with decisions made" and "Typified as intentional homicide"): "Even though I strongly agree with the decision, as a judge, if I was asked to intervene in the case, I would consider different situations that may relieve parties from liability; however, from a strictly dogmatic stance, it is an intentional homicide by negligence".

Judge (who selected "Strongly agree with decisions made" and "No crime typified"): "I believe this is a case established in the organ donation law".

Criminal defense lawyer (who selected "Disagree with decisions made", "Typified as failure to render assistance" and "Inciting a person to commit suicide"): "A matter to consider would be what sentence would be more benign towards parents and physicians".

Investigating judge (who selected "Strongly agree with decisions made" and "Typified as intentional homicide"): "A cause for justification that rules out illegality or a cause that would relieve parties from liability. Although the case fits the definition of intentional homicide, I would always look for a justification or a cause that would relieve parties from liability: a necessity 
based on the case-specific circumstances".

Judge (who selected "Disagree with decisions made" and "Typified as intentional homicide"): "Euthanasia represents the patient's right to decide how and when to die, but only seeking to relieve that person from intense suffering and merciless agony resulting from a severe and incurable disease. In Argentina, euthanasia is forbidden, unlike what occurs in Uruguay and The Netherlands, where a law has been passed to regulate it. Even though the Criminal Code projects submitted in 1937, 1941 and 1960 established that "mercy killing" should be differentiated from intentional homicide, euthanasia was not justified, it was still punishable, but differentiated based on its seriousness. Therefore, and based on current legislation, the case described here is punishable".

Investigating judge (who selected "Disagree with decisions made" and "Typified as intentional homicide"): "This crime is worsened because his parents are committing it and may be mitigated by an allegation of violent emotion".

\section{Degree of agreement with withdrawal} of mechanical ventilation, withdrawal of hydration and parenteral and/or enteral feeding, and change of opinion in the presence of advance medical directives requesting the withdrawal or withholding of mechanical ventilation or artificial hydration and feeding

Judge (who selected "Strongly agree with decisions made", "No crime typified" and "Would change my answer"): "Under the same circumstances of this case, i.e., if the parents knew about and agreed with his living will".

Judge (who selected "Disagree with decisions made" and refrained from commenting on the type of crime and indicated "Would change my answer"): "In this case, the patient is a 15-year-old adolescent. It would have been important to know that he did not want to live in that condition either".

Physician (who selected "Strongly agree with decisions made", "No crime typified" and "Would change my answer"): "For d) and e), I believe the decision is up to the parents, and physicians should collaborate with them to reach the best possible end when there are no chances of recovery".

Judge (who selected "Strongly agree with decisions made", "Typified as wrongful death" and "Would not change my answer"): "I would also ask for a consent document, and respect the patient's autonomy, will and freedom".

Public defender of minors and legally incompetent persons (who selected "Somewhat agree with decisions made", "No crime typified" and "Would change my opinion"): "If we assume that advance directives were made by a young adult (older than 14 years old)".

Appeal court judge (who selected "Disagree with decisions made", "Typified as wrongful death" and "Would not change my decision"): "It would be interesting to redefine the concept of pediatric patient".

Change of opinion in the case of adult patients

Physician (who selected "Strongly agree with decisions made", "No crime typified" and "Would change my answer"): "I would follow the patient's advance directives".

Physician (who selected "Strongly agree with decisions made", "No crime typified" and "Would not change my answer"): "Medicine should have a more humanistic rather than mechanistic approach. Major technological advances should not distort that approach. Technology should be at the service of life, not of death".

Oral trial court judge (who selected "Strongly agree with decisions made", "No crime typified" and "Would not change my answer"): "I would recommend palliative care. Until natural death occurs, I would privilege palliative care, including feeding and hydration".

Criminal defense lawyer (who selected "Disagree with decisions made", "Typified as failure to render assistance", "Inciting a person to commit suicide" and "Would change my answer"): "In the case of an adult, he/she may decide what to do with his/her life".

Investigating judge (who selected "Disagree with decisions made", "Typified as intentional homicide" and "Would change my answer"): "If the patient was elderly and had AMD".

\section{It is necessary to request legal authorization}

Judge (who selected "Strongly agree with decisions made", "Typified as wrongful death", "No crime typified" and "No need to require legal intervention"): "Medical science is suitable to make a diagnosis and establish the necessary procedures to manage the patient and decide what is right. Legal intervention would result in a delay and complications, worsening pain and distress for the family".

Judge (who selected "Somewhat agree with decisions made", "No crime typified" and "No need to require legal intervention"): "According 
to Molinario/Aguirre Obarrio, Pasteur was involved in a similar case (Molinario, Los delitos, volume I, page 122, Ed. TEA, 1996)".

Judge (who selected "Disagree with decisions made", "Typified as intentional homicide" and "Need to require legal intervention"): "Given that this is an action punished by criminal law, it is necessary to request authorization for each case in particular".

\section{Subjective findings}

Among the different opinions, it is worth noting that of a judge who indicated that health care decisions should be considered in the setting of the medical relationship, with no need to bring them before a judge. A different judge highlighted that his opinion in this case was different from that in the other two cases because he felt that the parents were the ones who did not want their son to be in that situation, and considered the selfishness component on their part. However, he stressed that, if he had this case in his court, he would probably consider the family's dramatic situation. A prosecutor indicated that withdrawal or withholding of life support was the result of the parents' interest, not that of the patient himself. He clarified that measures taken did not constitute a crime, but if the patient was breathing on his own, it would be a crime to withdraw feeding and hydration. On their side, physicians considered that this type of situations should not be brought to court, except they involved malpractice. A physician highlighted that intubation might have been withheld if that was the patient's decision, but if mechanical ventilation was needed from the beginning, he believed that the withdrawal of ventilation posed a more difficult situation.

Most respondents agreed on the withdrawal of mechanical ventilation (71.42\%). However, when asked about the withdrawal of hydration and feeding, either parenteral or enteral, the level of agreement changed: most were against withdrawal (65.31\% for parenteral feeding and $62.74 \%$ for enteral feeding), and this measure appeared to set the limit between what was acceptable and unacceptable regarding withdrawing or withholding treatment.

Phrases like "a situation with no reasonable chances of recovery" and "the patient is capable of making automatic gestures (smiling, wincing, etc.) but there is no recognizable relation to stimuli" raised concerns among survey respondents because they led respondents to believe that the situation was not as irreversible because the patient showed some sort of stimuli response.

In general, answers related to this case were very similar to those given in case 2 among those who disagreed with decisions made.

However, for some assumptions (22.22\%), even if respondents strongly agreed with decisions made, they only accepted the withdrawal of mechanical ventilation but not that of artificial hydration or feeding (enteral or parenteral).

No respondent changed his/her answer about the withdrawal of hydration or feeding (enteral or parenteral), even after explaining that one procedure was more invasive than the other.

For some assumptions, when asked if they would change their answer if the patient was an adult, they indicated that they would if the patient had advance medical directives.

\section{General subjective findings}

During the interviews, female respondents appeared to be much more concerned than men given that they invariably identified hypothetical subjects as their own children and attempted to find a reason to prevent the prosecution of parents and physicians.

Respondents who disagreed with decisions made believed that a legal authorization would not change things because it would be as requesting an "authorization to commit a crime".

Off the record, while chatting between questions during the interview, not only physicians would be accused of the typified crime, but parents would even be accused of being co-perpetrators and receive a longer sentence according to their relationship with the victim.

In relation to the type of profession, it is worth noting answers given by a criminal defense lawyer and a prosecutor. The defense lawyer disagreed with decisions made and criminalized actions but underscored the need to consider some sort of mitigation or waiver of liability while the prosecutor indicated he somewhat agreed with decisions made because he considered they did not constitute any form of crime. This appears to be contrary to what was "expected" from their roles given that a defense lawyer is believed to be more inclined to share the situations described while the prosecutor is expected to have a more critical approach.

A majority of representatives of the National Judiciary, either judges, defenders or prosecutors, 
expressed, especially when making comments and even though they criminalized decisions made, the possibility of such decisions being a privileged type of crime (violent emotion) or a justified therefore legal- behavior (informed consent provided by the patient or his/her parents in his/ her name) or a behavior that, although typical and illegal, was not reprehensible, either because a different behavior could not be required, it involved a prohibition mistake, or there was exculpatory evidence available. A vast majority $(88.23 \%)$ of respondents specifically stated the need to analyze the possibility of a sentence reduction and/or waiver of liability.
It is also worth noting that most respondents who criminalized one of the actions taken $(73.91 \%)$ indicated that they agreed with decisions made and that they understood the situation from a human perspective but considered it a crime from a strictly legal point of view.

Both lawyers and physicians highlighted the importance of asking an ethics committee to take part in decisions before even considering requesting a legal authorization. A major role in the health care relationship was assigned to these committees. 